\title{
Vulnerable personality and Takotsubo cardiomyopathy consequent to emotional stressful events: a clinical case report
}

\section{Personalità vulnerabile e Cardiomiopatia di Takotsubo successiva a stress emozionale: un caso clinico}

\author{
Angelo Compare ${ }^{1}$, Riccardo Proietti3 ${ }^{3}$ Domenico Del Forno², Alessandra Vitelli2, \\ Alessandra Grieco2, Luigi Maresca2, Francesco Giallauria2
}

\begin{abstract}
Vulnerable personality and Takotsubo cardiomyopathy consequent to emotional stressful events: a clinical case report. A. Compare, R. Proietti, D. Del Forno, A. Vitelli, A. Grieco, L. Maresca, F. Giallauria.

Introduction: Although the onset of Takotsubo cardiomyopathy (TTC) can be triggered by an acute, intense emotional stress, the exact pathogenic mechanisms still remain undefined.

Presentation: A 58-year-old female was sent by ambulance to the Emergency Department (ED) for chest pain and ST elevations on ECG. Her chest pain began 3 hours before on admission after a domestic argument. Transthoracic echocardiogram showed severe systolic dysfunction with an ejection fraction of $20 \%$. Cardiac catheterization revealed no significant coronary artery disease. The left ventriculogram showed apical ballooning with hyperdynamic proximal segments. A diagnosis of Takotsubo Cardiomyophaty (TTC) was made according to the Mayo Clinic 2008 criteria. The
\end{abstract}

patient evolved with improvement of her condition and, therefore, was discharged from the hospital. Follow-up echocardiogram seven days later showed normal LV size and function with ejection fraction (EF) of $43 \%$. Paykel Life Stress Event Scale identified as emotional trigger a domestic argument occurred 3 hours before symptom onset. History showed a major life stress event, death of a loved one, six months before symptoms. The patient underwent psychological assessment after hospital discharge by Emotional Regulation Questionnaire and BDI showing high suppression/ low reappraisal profile and moderate depression.

Conclusion: This case highlights the hypothesis of a possible link between cognitive emotional processing and vulnerability to Takotsubo syndrome.

Keywords: Takotsubo cardiomyopathy, personality traits, stressful event, emotional regulation, emotional trigger.

Monaldi Arch Chest Dis 2011; 76: 99-103.

\footnotetext{
1 University of Bergamo.

2 Department of Clinical Medicine, Cardiological and Immunological Science, University of Naples Federico II.

3 Electrophysiology Laboratory, Luigi Sacco Hospital, Milano, Italy.
}

Corresponding author: Prof. Angelo Compare; Corso di Laurea in Psicologia; Università di Bergamo; P.le S. Agostino, 2; I-24129 Bergamo, Italy; Fax: +39 0352052916; Mobile: +393283616304; E-mail address: angelo.compare@unibg.it

\section{Introduction}

The main feature of Takotsubo cardiomyopathy (TTC) is transient apical left ventricular dysfunction that mimics myocardial infarction, but in the absence of significant coronary artery disease. The onset of TTC can be triggered by an acute, intense emotional stress [1-5], but the exact pathogenic mechanisms linking emotional stress to TTC still remain undefined $[6,7]$. It is recognized that not all individuals are equally susceptible to stress-mediated cardiovascular events. Although a high prevalence of mood disorders in patient with TTC has been previously reported [8-13], however, studies specifically focused on analysing personality traits in TTC are still lacking.

\section{Case report}

A 58-year-old female was sent from a clinic by ambulance to the Emergency Department (ED) for chest pain and ST elevations on ECG. Her chest pain began 3 hours before on admission after a domestic argument. In the ED, vital signs were: blood pressure $(\mathrm{BP})$ of 132/86 $\mathrm{mm} \mathrm{Hg}$, pulse of 83 beats/min, respirations of 13 breaths/min, oxygen saturation (O2 sat) of $100 \%$ on 2 liters/minute via nasal cannula, and temperature of $37.3^{\circ} \mathrm{C}$. The chest pain was $6 / 10$, located substernally, and associated with shortness of breath (SOB), and radiated to her left arm. Her troponin I level was elevated at $2.5 \mathrm{ng} / \mathrm{ml}$ (normal: $<0.1 \mathrm{ng} / \mathrm{ml}$ ). Her electrocardiogram (ECG) on presentation showed sinus rhythm with $2 \mathrm{~mm} \mathrm{ST} \mathrm{el-}$ evations in V2 and V3 leads with q-waves. The patient immediately had cardiac catheterization with left ventriculography. Cardiac catheterization (Fig. 1) revealed no significant coronary artery disease. The left ventriculogram (Figure 1) showed apical ballooning with hyperdynamic proximal segments. This revealed an EF of $20 \%$ with only basal kinesis. Past medical history was unremarkable. Cardiac risks included 25 pack-years smoking, but she quit 5 


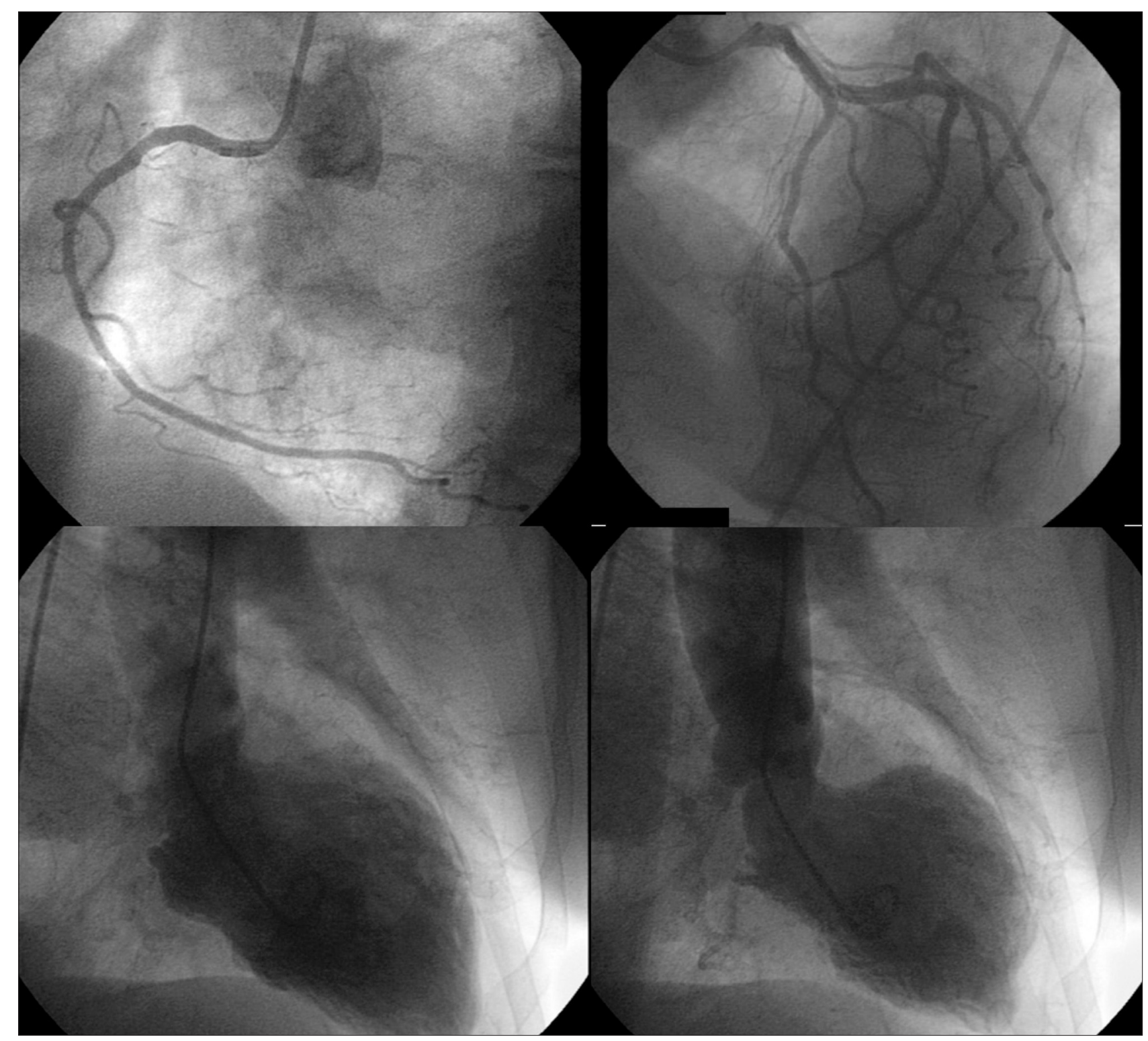

Figure 1. - Coronary arteriography: top left: right coronary artery; top right: left coronary artery. Left ventriculogram. (Botton left) The diastolic phase. (Botton right) The systolic phase showing apical ballooning with sparing of the apex with hyperdynamic basal segments, consistent with takotsubo cardiomyopathy.

years ago. No family history for heart disease was present. A diagnosis of Takotsubo Cardiomiophaty (TTC) was made according to the Mayo Clinic in 2004 and were modified in 2008 criteria. The patient evolved with improvement of her condition and, therefore, was discharged from the hospital. Followup echocardiogram seven days later showed normal $\mathrm{LV}$ size and function with ejection fraction (EF) of $43 \%$. A month later, the patient was asymptomatic in regard to her cardiovascular system. Control echocardiogram showed recovery of left ventricular function and mobility. At 4 months of follow-up, ECG and nuclear medicine tests were again repeated and showed no presence of impaired mobility or perfusion defects.

Emotional trigger event before symptom onset were identified using Paykel Life Stress Event Scale [14] at acute phase. Three hours before symptom onset emotional trigger, was an domestic argument. But anamnesis history showed a major life stress event, death of a loved one, six months before (Table 1). The patient underwent psychological assessment after hospital discharge by Emotional Regulation Questionnaire showing high suppression/ low reappraisal profile.

Depression and Emotional personality was assessed 2 week after the onset symptoms by Beck Depression Inventory (BDI) [15] and Emotion Regulation Questionnaire (ERQ) [16]. ERQ is a ten items (1-7 likert scale) measure of the habitual use expressive suppression (5-items) and cognitive reappraisal (5-items). Emotional Appraisal: Antecedent-focused regulation, in which intervention occurs early and is focused on altering the effect of
Table 1. - Stressful events at symptom onset and before

\begin{tabular}{lcc}
\hline & Symptom onset & Past Stressful event \\
\hline Emotional Trigger & $\begin{array}{c}\text { Domestic argument } \\
\text { (1 hour before })\end{array}$ & $\begin{array}{c}\text { Death of a loved one } \\
\text { (6 months before })\end{array}$ \\
\hline
\end{tabular}


Table 2. - Emotion regulation Questionnaire Profile

\begin{tabular}{|c|c|c|c|}
\hline & Score & Cut-off & Range \\
\hline \multicolumn{4}{|c|}{ Emotional Personality } \\
\hline Suppression & 30 & 20 & $5-35$ \\
\hline Reappraisal & 9 & 20 & $5-35$ \\
\hline BDI & 48 & 29 & $0-63$ \\
\hline
\end{tabular}

BDI= Beck Depression Inventory; *moderate depression

also clamping down on the expression of positive emotion [31]. At the same time, suppression will not be helpful in reducing the experience of negative emotion, which is not directly targeted by suppression and may thus continue to linger and accumulate unresolved. It requires the individual to effortfully manage emotion response tendencies as they continually arise. Moreover, suppression creates in the individual a sense of incongru-

emotion-generating cues [17]. This strategy modulates emotional response tendencies early on, before they give rise to full-fledged responses [18]. Cognitive reappraisal is an antecedent-focused strategy and involves construing a potentially emotion-eliciting situation in a way that changes its emotional impact. Emotional Suppression: Response-focused regulation, which acts late in the process and is focused on altering emotional output (e.g., action and expression) [17]. This strategy modulates the emotional responses themselves later on, once they have arisen. Expressive suppression is a response-focused strategy and refers to the inhibition of external cues to one's internal emotional state (e.g., facial expression, verbal utterances, gestures). It is a form of response modulation that involves inhibiting ongoing emotion-expressive behavior, typically with little or no change in ongoing emotion experience, and increased sympathetic activation of the cardiovascular system [19-21].

Patient showed an high level in suppression style $($ score $=30)$ and a low level in reappraisal style $($ score $=9)$ and moderate depression symptoms $($ score $=49)($ Table 2).

\section{Discussion}

The results of the present single case induce to hypothesize that emotional regulation personality based on suppression may be a potential vulnerable condition of Takotsubo reaction after emotional stressful event. Besides, inappropriate or ineffective emotion regulation is emerging as a critical component in the development and maintenance of depression disorder [22-27]. The present case report data reinforce recent findings revealing a high prevalence of depression $[8,28]$ in TTC patients preceding the onset of the acute cardiomyopathy. This is consistent with that data showing as individuals with depression have decreased vagal tone and an increased adrenomedullary hormonal response to stressful events [29] and appear to have very high noradrenaline spillover [30]. Suppression is associated with decreases in facial behavior and body movement and an increase in sympathetic activation of the cardiovascular system [19]. The Expressive Suppression strategy comes relatively late in the emotion-generative process, and primarily modifies the behavioral aspect of the emotion response tendencies. Suppression should thus be effective in decreasing the behavioral expression of negative emotion, but might have the unintended side effect of ence, or discrepancy, between inner experience and outer expression. Investigations of inhibitory control in human and nonhuman primates, however, suggest that the right ventrolateral prefrontal cortexis is associated with volitional response inhibition [32-39]. Over the long term, frequent use of expressive suppression results in diminished control of emotion and greater depressive symptomatology [16].

It is possible to hypothesize that the elevated level of suppression has contributed to the maintenance of the depressive symptom after the first major traumatic (death of a loved one), favoring the vulnerability to TTC by decreasing vagal tone and increasing adrenomedullary hormonal response to stressful events and noradrenaline spillover.

This case report is consistent with other available evidence affirming the pathophysiological importance of extreme sympathetic nervous system activation in TTC, suggesting that endothelial dysfunction is involved in mechanisms beyond high catecholamine levels [40]. Based on our results, it is reasonable to hypothesize that the origin of sympathetic hyperreactivity may be associated with specific personality emotional traits associate to high suppression. Thus, emotional regulation profile can be conceptualized as contributing to individual differences in cardiovascular reactivity to stress through sympathetic outflow to the heart, with cardiac noradrenaline spillover potentially achieving very high values [41].

\section{Conclusion}

This case highlights the possible link between Emotional Regulation personality and TTC reaction. This implies that the risk of an event may depend not only on the individual's cardiovascular vulnerability following stress exposure, but also on his or her coping mechanisms. The results suggest to analyze by well designed prospective case control studies if personality traits may be considered as markers of risk and routinely screened in the secondary prevention of TTC patients. However, these data suggest a personality vulnerable profile, based on cognitive style to process the emotions, that, by the link with depression symptoms, can make susceptible to physiological processes (e.g. heart rate, hormonal, or other physiological reactions), typical of TTC, after traumatic trigger. This implies that the risk of an event may depend not only on the individual's cardiovascular vulnerability following stress exposure, but also on his or her coping mechanisms. Findings of 
future researches will allow to establish pathophysiological constructs, and develop and test associated diagnostic and treatment models, so that these patients can be identified and appropriately treated.

\section{Riassunto}

Introduzione: Nonostante la cardiomiopatia di Takotsubo (TTC) può essere scatenata da uno stress emozionale acuto ed intenso, i meccanismi patogenici restano poco definiti.

Presentazione: Una donna di 58 anni viene trasferita in ambulanza al Pronto Soccorso con dolore toracico e sopraslivellamento del tratto ST-T all'ECG. Il dolore toracico si era manifestato 3 ore prima del ricovero dopo una lite domestica. L'ecocardiogramma mostrava una disfunzione sistolica severa con una frazione di eiezione ventricolare sinistra del 20\%. L'angiografia coronarica non rilevava una coronaropatia significativa. La ventricolografia sinistra mostrava ballooning apicale con segmenti prossimali iperdinamici. Veniva quindi posta diagnosi di cardiomiopatia di Takotsubo in accordo ai criteri della Mayo Clinic del 2008. Le condizioni cliniche della paziente miglioravano e quindi veniva dimessa. Il follow-up ecocardiografico 7 giorni dopo l' evento acuto mostrava dimensioni del ventricolo sinistro nei limiti con frazione di eiezione del 43\%. Utilizzando la Paykel Life Stress Scale, un trigger emozionale è stato identificato essere una lite domestica tre ore prima della comparsa dei sintomi. L'anamnesi ha evidenziato un evento maggiore di stress di vita come la perdita una persona cara 6 mesi prima dei sintomi. Dopo la dimissione ospedaliera, la paziente è stata sottoposta a valutazione psicologica mediante Emotional Regulation Questionnaire e BDI che hanno mostrato un profilo di elevata repressione/bassa rivalutazione e depressione di grado moderato.

Conclusioni: Questo caso conferma il collegamento tra il processing emozionale cognitivo e la vulnerabilitá alla sindrome di Takotsubo.

\section{ABBREVIATIONS LIST}

Takotsubo cardiomyopathy (TTC)

Paykel Life Stress Events Scale (PLSE)

Emotional Regulation Questionnaire (ERQ)

Beck Depression Inventory (BDI)

\section{References}

1. Sharkey SW, Lesser JR, Menon M, et al. Spectrum and significance of electrocardiographic patterns, troponin levels, and thrombolysis in myocardial infarction frame count in patients with stress (tako-tsubo) cardiomyopathy and comparison to those in patients with ST-elevation anterior wall myocardial infarction. Am J Cardiol 2008; 101(12): 1723-8.

2. Connelly KA, MacIsaac AI, Jelinek VM. Stress, myocardial infarction, and the "tako-tsubo" phenomenon. Heart 2004; 90(9): e52.

3. Wittstein IS, Thiemann DR, Lima JA, et al. Neurohumoral features of myocardial stunning due to sudden emotional stress. N Engl J Med 2005; 352(6): 539-48.

4. Yaghoubi AR, Ansarin K, Hashemzadeh S, et al. Takotsubo cardiomyopathy induced by emotional stress leading to severe mitral regurgitation, cardiogenic shock and cardiopulmonary arrest. Int J Cardiol 2009; 135(3): e85-6.

5. Nef HM, Mollmann H, Hilpert P, et al. Sympathoadrenergic overstimulation in Tako-Tsubo cardiomyopathy triggered by physical and emotional stress. Int J Cardiol 2008; 130(2): 266-8.

6. Abraham J, Mudd JO, Kapur NK, et al. Stress cardiomyopathy after intravenous administration of catecholamines and beta-receptor agonists. J Am Coll Cardiol 2009; 53(15): 1320-5.

7. Wittstein IS. Acute stress cardiomyopathy. Curr Heart Fail Rep 2008; 5(2): 61-8.

8. Mudd JO, Kapur NK, Champion HC, Schulman SP, Wittstein IS. Patients with Stress-Induced (Takotsubo) Cardiomyopathy Have an Increased Prevalence of Mood Disorders and Antidepressant Use Compared to Patients with Acute Myocardial Infarction. Journal of Cardiac Failure 2007; 13(6, Supplement 2): S176.

9. Regnante RA, Zuzek RW, Weinsier SB, et al. Clinical characteristics and four-year outcomes of patients in the Rhode Island Takotsubo Cardiomyopathy Registry. Am J Cardiol 2009; 103(7): 1015-1019.

10. Vidi V, Rajesh V, Singh PP, et al. Clinical Characteristics of Tako-Tsubo Cardiomyopathy. Am J Cardiol 2009; 104(4): 578-582.

11. Sobnosky S, Shah A, Aharonian VJ, et al. Abstract 20134: Frequency of Psychiatric Disorders in Persons With Stress Induced Cardiomyopathy. Circulation 2010; 122(21_MeetingAbstracts): A20134.

12. Summers MR, Lennon RJ, Prasad A. Pre-Morbid Psychiatric and Cardiovascular Diseases in Apical Ballooning Syndrome (Tako-Tsubo/Stress-Induced Cardiomyopathy): Potential Pre-Disposing Factors? J Am Coll Cardiol 2010; 55(7): 700-701.

13. Del Pace S, Parodi G, Bellandi B, et al. Anxiety trait in patients with stress-induced cardiomyopathy: a case-control study. Clin Res Cardiol 2011.

14. Paykel E. Life events: effects and genesis. Psychol Med 2003; 33(7): 1145-8.

15. Beck AT, Steer RA, R. Ball, and W. Ranieri, Comparison of Beck Depression Inventories -IA and -II in psychiatric outpatients. J Pers Assess 1996; 67(3): 588-97.

16. Gross JJ, John OP. Individual differences in two emotion regulation processes: implications for affect, relationships, and well-being. J Pers Soc Psychol 2003; 85(2): 348-62.

17. Moore SA, Zoellner LA, Mollenholt N. Are expressive suppression and cognitive reappraisal associated with stress-related symptoms? Behav Res Ther 2008; 46(9): 993-1000.

18. Goldin PR, McRae K, Ramel W, Gross JJ. The neural bases of emotion regulation: reappraisal and suppression of negative emotion. Biol Psychiatry 2008; 63(6): 577-86.

19. Demaree HA, Schmeichel BJ, Robinson JL, et al. Upand down-regulating facial disgust: affective, vagal, sympathetic, and respiratory consequences. Biol Psychol 2006; 71(1): 90-9.

20. Gross JJ. Emotion regulation: affective, cognitive, and social consequences. Psychophysiology 2002; 39(3): 281-91.

21. Gross JJ, Levenson RW. Emotional suppression: physiology, self-report, and expressive behavior. J Pers Soc Psychol 1993; 64(6): 970-86.

22. Barlow DH, Allen LB, ChoateML. Toward a unified treatment for emotional disorders. Behavior Therapy 2004; 35: 205-230.

23. Campbell-Sills L, Barlow DH, Brown TA, Hofmann SG. Acceptability and suppression of negative emotion in anxiety and mood disorders. Emotion 2006; 6(4): 587-95.

24. Campbell-Sills L, Barlow DH, Brown TA, Hofmann SG. Effects of suppression and acceptance on emotional responses of individuals with anxiety and mood disorders. Behav Res Ther 2006; 44(9): 1251-63. 
25. Kashdan TB, Barrios V, Forsyth JP, Steger MF. Experiential avoidance as a generalized psychological vulnerability: comparisons with coping and emotion regulation strategies. Behav Res Ther 2006; 44(9): 1301-20.

26. Kashdan TB, Steger MF. Expanding the topography of social anxiety. An experience-sampling assessment of positive emotions, positive events, and emotion suppression. Psychol Sci 2006; 17(2): 120-8.

27. Mennin DS. Emotion regulation therapy: an integrative approach to treatment-resistant anxiety disorders. Journal of Contemporary Psychotherapy 2006; 36: 95-105.

28. Summers MR, Lennon RJ, Prasad A. Pre-Morbid Psychiatric and Cardiovascular Diseases in Apical Ballooning Syndrome (Tako-Tsubo/Stress-Induced Cardiomyopathy): Potential Pre-Disposing Factors? J Am Coll Cardiol 55(7): 700-701.

29. Cevik C, Nugent K. The role of cardiac autonomic control in the pathogenesis of tako-tsubo cardiomyopathy. Am Heart J 2008; 156(3): e31-Cevik, Cihan.

30. Barton DA, Dawood T, Lambert EA, et al. Sympathetic activity in major depressive disorder: identifying those at increased cardiac risk? J Hypertens 2007; 25(10): 2117-2124.

31. Roberts NA, Levenson RW, Gross JJ. Cardiovascular costs of emotion suppression cross ethnic lines. Int J Psychophysiol 2008; 70(1): 82-7.

32. Brass M, Derrfuss J, von Cramon DY. The inhibition of imitative and overlearned responses: a functional double dissociation. Neuropsychologia 2005; 43(1): 89-98.

33. Buchsbaum BR, Greer S, Chang WL, Berman KF. Metaanalysis of neuroimaging studies of the Wisconsin cardsorting task and component processes. Hum Brain Mapp 2005; 25(1): 35-45.
34. Elliott R, Deakin B. Role of the orbitofrontal cortex in reinforcement processing and inhibitory control: evidence from functional magnetic resonance imaging studies in healthy human subjects. Int Rev Neurobiol 2005; 65: 89-116.

35. Garavan H, Hester R, Murphy K, Fassbender C, Kelly C. Individual differences in the functional neuroanatomy of inhibitory control. Brain Res 2006; 1105(1): 130-42.

36. Kelly AM, Hester R, Murphy K, et al. Prefrontal-subcortical dissociations underlying inhibitory control revealed by event-related fMRI. Eur J Neurosci 2004; 19(11): 3105-12.

37. Li CS, Huang C, Constable RT, Sinha R. Imaging response inhibition in a stop-signal task: neural correlates independent of signal monitoring and post-response processing. $J$ Neurosci 2006; 26(1): 186-92.

38. Rubia K, Smith AB, Brammer MJ, Taylor E. Right inferior prefrontal cortex mediates response inhibition while mesial prefrontal cortex is responsible for error detection. Neuroimage 2003; 20(1): 351-8.

39. Vollm B, Richardson P, McKie S, et al. Serotonergic modulation of neuronal responses to behavioural inhibition and reinforcing stimuli: an fMRI study in healthy volunteers. Eur J Neurosci 2006; 23(2): 552-60.

40. Martin EA, Prasad A, Rihal CS, Lerman LO, Lerman A. Endothelial function and vascular response to mental stress are impaired in patients with apical ballooning syndrome. J Am Coll Cardiol 56(22): 1840-6.

41. Baumert M, Lambert GW, Dawood T, et al. Short-term heart rate variability and cardiac norepinephrine spillover in patients with depression and panic disorder. Am J Physiol Heart Circ Physiol 2009; 297(2): H674-9. 